$4-11-2017$

\title{
Unmet need for surgery in South Asia
}

\author{
Sanjay Nagral \\ Jaslok Hospital and Research Centre, Mumbai, India \\ Maharra Hussain \\ Mediclinic Welcare Hospital, Dubai, United Arab Emirates \\ Sarder A. Nayeem \\ Japan Bangladesh Friendship Hospital, Dhaka, Bangladesh \\ Ranjan Dias \\ Lady Ridgeway Hospital for Children, Colombo, Sri Lanka \\ Ather Enam \\ Aga Khan University, ather.enam@aku.edu
}

See next page for additional authors

Follow this and additional works at: https://ecommons.aku.edu/pakistan_fhs_mc_surg_neurosurg

Part of the Neurology Commons, Neurosurgery Commons, and the Surgery Commons

\section{Recommended Citation}

Nagral, S., Hussain, M., Nayeem, S. A., Dias, R., Enam, A., Nundy, S. (2017). Unmet need for surgery in South Asia. BMJ : British medical journal, 357, j1423.

Available at: https://ecommons.aku.edu/pakistan_fhs_mc_surg_neurosurg/107 


\section{Authors}

Sanjay Nagral, Maharra Hussain, Sarder A. Nayeem, Ranjan Dias, Ather Enam, and Samiran Nundy 


\title{
Unmet need for surgery in South Asia
}

\author{
Despite increased specialisation and technology, surgical care in the world's most populous \\ region is inequitable and remains inaccessible to most people, say Sanjay Nagral \\ and colleagues
}

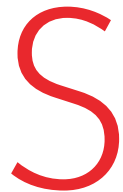

urgical disorders are a substantia burden. Surgery is a cost effective method to return sick and injured people to health and work. ${ }^{1}$ The Lancet Commission on Global Surgery reports that nearly a third of the global burden of disease can be attributed to surgically treatable conditions. ${ }^{2}$ South Asia has the highest unmet surgical need in the world,,$^{2}$ and surgical care is out of reach for most people. This is because of the political economy of the region, which has produced an underfunded and inefficient public sector and a dominant private sector. ${ }^{3}$ Reforming surgical care is therefore a priority for the region.

In this article, we review the rapidly changing situation of surgical care in South Asia. Although recent high quality regional data on the surgical infrastructure, workforce, and outcomes are lacking, there are several cultural, financial and structural barriers that prevent access to surgery. ${ }^{4} \mathrm{We}$ propose a course of action for the surgical community and governments of the region to improve the accessibility, equity, and quality of surgical care in South Asia.

\section{Epidemiology of surgical disease}

Surgical disease in South Asia is characterised by late presentation and coexisting malnutrition. ${ }^{5}$ Patients with cancer tend to present at a much later stage of the disease than in the developed world. ${ }^{6}$ The region also has a large burden of infectious diseases such as amoebic liver abscess, worm infestation, filariasis, and leprosy, many of which need surgery. Furthermore, non-communicable diseases and rapid urbanisation

\section{KEY MESSAGES}

Increased specialisation and technology but severe lack of access and uneven growth characterise surgery in South Asia Strategies such as task sharing, using low cost technology, and developing locally appropriate procedures could lower costs and improve access

The surgical community must acknowledge that lack of access to surgical care is a serious public health problem needing increased funding and prioritisation by governments in the region have increased the burden on surgical services. In the past few decades, there has been a rise in non-communicable diseases such as diabetes, hypertension, and ischaemic heart disease. These may require surgery, but they also increase the risks of surgical procedures. ${ }^{7}$ A rapid increase in motor vehicles, unregulated traffic and poor safety measures have led to more road traffic injuries, which also may need surgery. ${ }^{8}$

\section{Surgical infrastructure in South Asia}

Surgical care is characteristic of the inequity of healthcare in the region. The underfunded care available to poor people in public hospitals, especially in rural areas, contrasts starkly with the advanced, high tech care for wealthy people in private hospitals.

A national health facility survey in India showed a severe lack of resources at the first level referral hospitals: 39\% of primary health centres did not have an operating room, 19\% of district hospitals did not have a surgeon, 83\% did not have an anaesthetist, $91 \%$ did not have a blood storage facility, and none met the criteria of well-resourced hospitals. ${ }^{9}$ The situation in urban areas, although marginally better, is still uneven.

This has undesirable consequences. A study from Pakistan estimated that there were 187 deaths per 100000 persons per year from acute surgical illnesses, which was higher than deaths from infectious diseases, including tuberculosis, HIV/AIDS, diarrhoeal disease, and childhood infections. ${ }^{10}$ Analysis of a subset from the Million Death Study in 2015 showed that people living in remote areas of India were often late in accessing care for routine emergencies like bowel perforation, which led to a large number of preventable deaths. ${ }^{11}$ For people injured in road traffic crashes, there is a lack of care at the incident, organised referral, and transport leading to a high number of deaths. ${ }^{9}$

Mass surgical "camps", where teams from urban centres perform surgery on large numbers of patients in remote areas at minimal or no costs, are a feature of surgical practice in South Asia. This model has been widely used for cataract surgery and sterilisation for population control. However, complications from performing operations in this way have occurred. ${ }^{12}$ Charitable and faith based organisations have helped bridge the gap in surgical care not covered by state agencies or private players. ${ }^{1314}$ Such initiatives, although praiseworthy, cannot replace a strong, publicly funded system of care.

\section{Increase in advanced surgery and medical tourism}

In the past 10 years, there has been a substantial increase in surgery in the region, with more complicated procedures being performed with advanced technology. Large private hospitals with high tech equipment have attracted surgeons as well as the emerging middle class. ${ }^{15}$ Private hospital chains offering high quality healthcare have grown. ${ }^{16}$ These attract patients from overseas, especially the Middle East and Africa, and occasionally from Europe and North America, because the costs are far lower. ${ }^{15}$

With a changing culture and lifestyle, cosmetic, bariatric, and arthroscopic surgery have grown considerably. In the absence of any regulations, supplier induced demand and unnecessary procedures have increased. ${ }^{17}$ For example, a cross-sectional analysis of data from Bangladesh, India, and Nepal showed higher rates of caesarean section in private healthcare facilities than in public ones, even when adjusted for pregnancy, delivery, maternal characteristics and year of delivery. ${ }^{18}$

This uncontrolled growth is largely driven by market forces, and has worsened the uneven distribution and inequity of surgical care in the region. ${ }^{16}$ For those who can afford it, advanced surgery, such as cancer surgery, transplantation for organ failure and functional brain surgery, now offers hope for diseases that until recently had a very poor prognosis. This has, however, increased costs substantially. Most patients have no health insurance, and the cost of surgery is a major contributor to financial problems. Of concern is the lack of impetus to measure and report on the cost effectiveness of these complex surgical procedures. ${ }^{19}$

\section{Shortages in the surgical workforce}

Specialised surgery has grown partly at the expense of basic general surgery. Surgeons are specialising in areas such as cardiac surgery and organ transplantation because they are well paid or glamorous compared with areas such as trauma care. New areas such 
as oncosurgery, joint replacement, paediatric cardiac surgery, and vitreoretinal surgery have emerged. Given the well paid career opportunities in the private sector, it is unlikely that postgraduate surgeons will willingly work in underserved areas. The region also continues to lose surgeons through migration to Western countries and the Middle East.

The lack of a trained workforce has a greater effect on surgical care than on other fields of medicine. As governments subsidise medical education in the region, one solution that has been tried, with varying success, is requiring surgeons to work in underserved areas as part of their postgraduate training.

\section{Quality and safety of surgery in South Asia}

Quality and safety in surgery are low on the health agenda in South Asia even though there is now a global focus on surgical safety, enhanced recovery, and quality of life. ${ }^{2021}$ No mechanism exists for regular audits of complications after common operations. Countries lack comprehensive national databases of surgical procedures and outcomes. A higher incidence of complications in routine procedures has been reported in South Asia than in the developed world..$^{22}$ Surgical oncology data in India show poor survival rates in patients with cancer. ${ }^{6}$ The uncontrolled use of antibiotics in Asian countries has made hospital infection rates with multidrug resistant bacteria among the highest in the world. ${ }^{23}$

Academic surgical departments are still largely in public hospitals, although training, especially in subspecialties, is increasingly being offered in private hospitals. However, there is no robust system to monitor uniformity and quality of training. ${ }^{24}$ Most postgraduate surgical programmes require students to do a research based thesis, but very few of these are published or affect surgical practice..$^{25}$

\section{Bridging the gaps}

The Lancet Commission on Global Surgery supports integration of surgical services in all basic universal health coverage plans with targets for 2030 of providing $80 \%$ coverage of essential surgical and anaesthesia services and $100 \%$ protection against catastrophic out-of-pocket expenditure. ${ }^{2}$ In South Asia, where healthcare is traditionally low on the political agenda, countries will have to make universal health care a priority in order to meet these targets.

In India, publicly financed health insurance schemes for surgical treatment have been introduced in some states. ${ }^{2627}$ These have improved surgical coverage for poor people, although occasionally they have led to unnecessary procedures. ${ }^{28}$ Such mass insurance schemes can potentially improve and regulate standards of surgical care. For example, the Rajeev Gandhi Jeevandayee Arogya Yojana scheme promotes the use of the WHO surgical safety checklist and does not pay for hysterectomies in the private sector.

Given limited resources, a major challenge is to provide evidence based and up-to-date surgical care while containing costs and ensuring access. We recommend creating locally appropriate and cost effective treatment procedures. For example, the use of costly diagnostic procedures such as computed tomography and positron emission tomography scans for staging cancers can be limited and the use of expensive devices like staplers avoided without compromising care. Innovative solutions such as reusing costly disposable equipment and using cheaper local alternatives like mosquito nets instead of synthetic meshes for hernia repairs must be studied and encouraged. ${ }^{329}$

The use of graduates with a basic medical degree to provide surgical care should be considered. While the monopoly of postgraduate surgeons in delivering surgical care could be protected for specialised work, basic and emergency care could be opened up. Medical graduates and complementary medicine practitioners working in underserved areas can be trained to perform simple surgical procedures. Expansion of the surgical workforce by creating teams of trained support staff has been shown to improve care in settings with limited resources. ${ }^{30}$ Health workers without formal medical education provide much of the primary care in rural areas. Increasing their skills may help overcome the shortage of skilled staff to assist with basic surgery in underserved areas. Public-private partnerships have developed teams of trained paramedics for emergency and trauma care and their services will be crucial to reduce deaths from road traffic or unintentional injuries. ${ }^{31}$

\section{International and regional collaborations}

Generally, surgeons from South Asia have trained in developed countries, and surgical teams from the West have helped set up surgical units in the region. The Royal Colleges of Surgeons in the United Kingdom have strong academic ties with local bodies in South Asia. Using these international collaborations could help improve the quality of surgical training and practice in South Asia.

It is unlikely that countries in the region can offer substantial direct help to each other to reduce unmet surgical needs. However, countries should be encouraged to learn from successful models of accessible surgical care. Regional cooperation among the surgical community is informal and limited to meetings or training workshops. National surgical associations in the region largely focus on organising meetings for exchange of knowledge or surgical skills. A Surgical Care Society within the South Asian Association for Regional Cooperation was established in 1996 and has organised conferences across the region. ${ }^{29}$ These societies have not tackled the lack of access to surgery as an issue. Their mandate must widen to identify common regional problems and create a joint platform for advocacy and action.

\section{Conclusion}

The combination of severe shortages and deficiencies in surgical care in poor areas and expensive and sometimes unnecessary surgery in the unregulated private sector presents two challenges for South Asia. Health advocacy and policy in the region have largely focused on areas like maternal and child health and infectious diseases. It is time the surgical community took the lead to highlight the imbalance in surgical care and the need for urgent state intervention. Importantly, the surgical community must recognise the public health importance of surgical care. Opportunities to train health workers in basic surgical procedures and trauma care must be explored. Attention to the global focus on outcomes and safety is essential.

In the South Asian culture, surgeons are prominent citizens and their associations have considerable influence with the state authorities. They should use this to push policy towards access and quality. A unified voice from regional surgical societies may help. We appeal to the surgical community of the region to recognise and take up this challenge so that the benefits of the extraordinary global advances in surgery reach those who need them the most.

Contributors and sources: The authors are senior surgeons working in the South Asian region. They have been active in regional surgical forums, engaged with policy makers and written on the subject. This article evolved from a concept note and literature review. S Nagral prepared the concept note and is the guarantor of the paper, $\mathrm{MH}$ was involved in the research and literature review, RD provided information on Sri Lanka and contributed to the draft, SAE provided information on Pakistan and contributed to the draft, S Nayeem provided information on Bangladesh and contributed to the draft, and S Nundy contributed to and edited the concept note and final draft.

Competing interests: We have read and understood BMJ policy on declaration of interests and have no relevant interests to declare.

Provenance and peer review: Commissioned; externally peer reviewed.

Sanjay Nagral, senior consultant ${ }^{1}$

Maharra Hussain, specialist general surgeon ${ }^{2}$ Sarder A Nayeem, chief laparoscopic surgeon ${ }^{3}$ Ranjan Dias, senior lecturer in paediatric surgery ${ }^{4}$ S Ather Enam, professor of neurosurgery ${ }^{5}$ 
Samiran Nundy, senior consultant 6

'Department of Surgical Gastroenterology, Jaslok Hospital and Research Centre, Mumbai, India

2Department of Surgery, Mediclinic Welcare Hospital, Dubai, United Arab Emirates

${ }^{3}$ Japan Bangladesh Friendship Hospital (JBFH), Dhaka, Bangladesh

${ }^{4}$ University of Colombo, Lady Ridgeway Hospital for Children, Colombo, Sri Lanka

${ }^{5}$ Department of Surgery, The Aga Khan University, Karachi, Pakistan

${ }^{6}$ Department of Surgical Gastroenterology and Liver Transplantation, Sir Ganga Ram Hospital, New Delhi, India

Correspondence to: S Nagral sanjaynagral@gmail.com

1 Schecter WP, Adhikari S. Global surgery and poverty. In: Debas HT, Donkor P, Gawande A, Jamison DT, Kruk ME, Mock CN, eds. Essential surgery: disease control priorities.3rd ed. International Bank for Reconstruction and Development, World Bank, 2015:353-9. doi:10.1596/978-1-4648-0346-8 ch20.

2 Meara JG, Leather AIM, Hagander L, et al. Global Surgery 2030: evidence and solutions for achieving health, welfare, and economic development. Lancet 2015;386:569-624. doi:10.1016 S0140-6736(15)60160-X

3 Sengupta A, Mukhopadhyaya I Weerasinghe MC, Karki A. The rise of private medicine in South Asia. BMJ 2017;:357:j1482.

4 Grimes CE, Bowman KG, Dodgion CM, Lavy CB. Systematic review of barriers to surgical care in low-income and middle-income countries. World Surg 2011;35:941-50. doi:10.1007 s00268-011-1010-1.

5 Lancet Commission on Global Surgery. Teaching case. Surgical care for low-income, rural populations: an alternative delivery model from Jan Swasthya Sahyog, India. http://www.globalsurgery.info/wp-content/ uploads/2015/09/India-Teaching-Case.pdf

6 Goss PE, Strasser-Weippl K, Lee-Bychkovsky BL, et al. Challenges to effective cancer control in China, India, and Russia. Lancet Oncol 2014;15:489-538. doi:10.1016/S1470-2045(14)70029-4

7 Misra A, Tandon N, Ebrahim S, et al. Diabetes, cardiovascular disease, and chronic kidney disease in South Asia: current status and future directions BMJ 2017:357:11420

8 Nambir D, Razzak J,, Afsana KAdams A, Hasan A, Mohan D, Patel K. Mental illness and injuries: emerging health challenges of urbanisation in South Asia. BMJ 2017;357:j1126
9 International Institute for Population Sciences. District level household and facility survey (DLHS-3), 2007-08. 2010. http://www.rchiips.org/pdf/INDIA_REPORT_ DLHS-3.pdf

10 Ahmed M, Shah M, Luby S, Drago-Johnson P, Wali S. Survey of surgical emergencies in a rural population in the Northern Areas of Pakistan. Trop Med Int Health 1999;4:846-57. doi:10.1046/i.1365-3156.1999.00490x

11 Dare AJ, Ng-Kamstra JS, Patra J, et al. Million Death Study Collaborators. Deaths from acute abdominal conditions and geographical access to surgical care in India: a nationally representative spatial analysis. Lancet Glob Health 2015;3:e646-53. doi:10.1016/ S2214-109X(15)00079-0.

12 Pulla P. Why are women dying in India's sterilisation camps?BM/ 2014;349:g7509. doi:10.1136/bmi.g7509.

13 Bhandari A, Dratler S, Raube K, Thulasiraj RD. Specialty care systems: a pioneering vision for global health. Health Aff (Millwood) 2008;27:964-76. doi:10.1377/ hlthaff.27.4.964.

14 Samad L, Iqbal M, Tariq A, Shahzad W, Khan Al. Equitable access to comprehensive surgical care: the potential of indigenous private philanthropy in low-income settings. World J Surg 2015;39:21-8 doi:10.1007/s00268-014-2852-0.

15 Sengupta A, Nundy S. The private health sector in India. Burgeoning at the cost of public health care. BMJ 2005;331:157-8doi:10.1136/bmj.331.7526.1157.

16 Ahmed M, Raja A, Nundy S. Surgery in South Asia: A private complication of a public problem. BM 2004:328:782. doi:10.1136/bmi.328.7443.782.

17 Desai S, Sinha T, Mahal A. Prevalence of hysterectomy among rural and urban women with and without health insurance in Gujarat, India. Reprod Health Matters 2011:19:42-51. doi:10.1016/ S0968-8080(11)37553-2.

18 Neuman M, Alcock G, Azad K, et al. Prevalence and determinants of caesarean section in private and public health facilities in underserved South Asian communities: cross-sectional analysis of data from Bangladesh, India and Nepal. BMJ Open 2014;4:e005982. doi:10.1136/ bmjopen-2014-005982.

19 Prinja S, Nandi A, Horton S, Levin C, Laxminarayan R. Costs, effectiveness, and cost-effectiveness of selected surgical procedures and platforms. In: Debas HT, Donkor P, Gawande A, Jamison DT, Kruk ME, Mock CN, eds. Essential surgery: disease control priorities. 3rd ed. International Bank for Reconstruction and Development, World Bank, 2015:317-338.

20 Nanavati AJ, Nagral S. Why have we embraced minimally invasive surgery and ignored enhanced recovery after surgery?] Minim Access Surg 2016;12:299-301. doi:10.4103/0972-9941.181392.
21 Nanavati AJ, Nagral S, Prabhakar S. Fast-track surgery in India. Natl Med J India 2014;27:79-83.

22 Weiser TG, Gawande A. Excess surgical mortality: strategies for improving quality of care. In: Debas HT, Donkor P, Gawande A, Jamison DT, Kruk ME, Mock CN, eds. Essential surgery: disease control priorities. 3rd ed. International Bank for Reconstruction and Development, World Bank, 2015:279-305.

23 Morrissey I, Hackel M, Badal R, Bouchillon S, Hawser S, Biedenbach D. A Review of Ten Years of the Study for Monitoring Antimicrobial Resistance Trends (SMART) from 2002 to 2011. Pharmaceuticals (Basel) 2013:6:1335-46. doi:10.3390/ph6111335.

24 Tandon A. Postgraduate surgical training in India. Indian J Med Ethics 2010;7:264-5.

25 Ray S, Shah I, Nundy S. The research output from Indian medical institutions between 2005 and 2014 Curr Med Res Pract. 2016:6:4-6doi:10.1016/j. cmrp.2016.04.002

26 Public Health Foundation of India. A critical assessment of the health insurance models in India. 2011. http://planningcommission.nic.in/reports/ sereport/ser/ser_heal1305.pdf

27 Devadasan N, Criel B, Van Damme W, Ranson K, Van der Stuyft P. Indian community health insurance schemes provide partial protection against catastrophic health expenditure. BMC Health Serv Res 2007;7:43. doi:10.1186/1472-6963-7-43.

28 Mamidi BB, Pulla V. Hysterectomies and violation of human rights: case study from India. Int I Social Work Hum Serv Pract 2013;1:64-75. doi:10.13189/ ijrh.2013.010110

29 Saeed M. SAARC surgical professionals' meet. World Trade Rev 2003;19.

30 Beard JH, Oresanya LB, Akoko L, Mwanga A, Mkony CA, Dicker RA. Surgical task-shifting in a low-resource setting: outcomes after major surgery performed by nonphysician clinicians in Tanzania. World J Surg 2014;38:1398-404. doi:10.1007/s00268-013-2446-2.

31 Brown HA, Douglass KA, Ejas S, Poovathumparambil V. Development and implementation of a novel prehospital care system in the State of Kerala, India. Prehosp Disaster Med 2016;31:663-6. doi:10.1017/ S1049023X16000960.

32 Hussain M, Balsara KP, Nagral S. Reuse of single-use devices: looking back, looking forward. Natl Med J India 2012;25:151-5.

33 Löfgren J, Nordin P, Ibingira C, Matovu A, Galiwango E, Wladis A. Ibingira, Matovu A, Galiwango E, Wladis A. A randomized trial of low-cost mesh in groin hernia repair. N Engl / Med 2016;374:146-53. doi:10.1056/ NEJMoa1505126.

Cite this as: BMJ 2017;357:j1423

http://dx.doi.org/10.1136/bmj.j1423 